\title{
The Present Situation, Problems and Policy Suggestions of the Development of Heze E-commerce
}

\author{
Xiumin Ye \\ Institute of Quantitative \& Technical Economics Chinese Academy of Social Sciences, Beijing, China \\ Email address: \\ xmye@cass.org.cn \\ To cite this article: \\ Xiumin Ye. The Present Situation, Problems and Policy Suggestions of the Development of Heze E-commerce. Humanities and Social \\ Sciences. Vol. 6, No. 2, 2018, pp. 68-75. doi: 10.11648/j.hss.20180602.14
}

Received: April 30, 2018; Accepted: May 10, 2018; Published: June 20, 2018

\begin{abstract}
At present, our country's economy has developed to the key period of transformation and upgrading. The main task of the current economic is to work to excavate the economic growth point and cultivate new kinetic energy. The rural areas are faced with dual tasks of economic and social transformation. "The Nineteen Congress of the People's Congress" report puts forward the strategy of "Implementing Rural Revitalization", which requires the priority of agricultural and rural development and accelerate the modernization of agriculture and rural areas. In order to find the breakthrough point of rural revitalization, the author has been engaged in a lot of field investigation and research for many years. Through the practical experience of the development of electronic commerce in various places, the author summarizes the role and law of e-commerce to the rural economy and social development. Through field investigation and visit, this paper combs the current situation of the development of electronic commerce in Heze through case study, summarizes the experience of Heze in the process of e-commerce development, which has an important inspiration for the development of rural e-commerce in other areas. In the course of the investigation, there are also some problems in the development process of Heze rural e-commerce, such as the lack of competitiveness, lack of talent, the difficulty of enterprise financing, etc., and put forward four policy suggestions to promote the transformation of traditional enterprises, cultivate the leading enterprises of Internet business, and encourage financial innovation.
\end{abstract}

Keywords: E-Commerce, Entrepreneurship and Employment, "Internet Plus"

\section{Introduction}

\subsection{China's e-Commerce Has Made Breakthrough Progress}

E-commerce in China has made great progress during the "12th Five-Year" period. It has become a new driving force for economic development. With the push of "Internet Plus" plan, it has set off a new upsurge in the application of e-commerce all over the country. There are many cities in the application of e-commerce, some cities have the aid of e-commerce to promote the transformation of traditional industries, and some cities are promoting e-commerce to overtake the curve through the promotion of e-commerce. Summing up the experience and shortcomings of these cities has important practical significance for continuing to guide the in-depth application of e-commerce.

\subsubsection{The Scale of e-Commerce Annual Transactions Continues to Grow, Becoming an Important Component of the National Economy}

The volume of e-commerce transactions in China amounted to 29 trillion and 160 billion Yuan, equivalent to $35.49 \%$ of GDP in 2017. The volume of e-commerce transactions increased by $11.7 \%$ over the same period last year. Compared with the growth rate of GDP of $6.9 \%$, e-commerce is still a new driving force for China's economic growth. The size of the online retail market continued to expand, with a volume of 7 trillion Yuan, equivalent to $22.84 \%$ of the total retail sales of consumer goods in the year, up 7.3 percentage points over the previous year. The online retail market maintained a rapid growth rate, an increase of $39.14 \%$ over the same period last year, 4 times and the total retail sales of consumer goods. 


\subsection{2. "Internet Plus" Actions Has Promoted the Traditional Industry and e-Commerce Integration Development}

On the one hand, traditional enterprises expand their marketing channels through e-commerce. On the other hand, e-commerce can reduce procurement costs and improve procurement efficiency. The scale of enterprise online shopping reached 15 trillion and 100 billion Yuan in 2016, an increase of $22.1 \%$ over the same period last year. Shendong Coal Group made a cable deal worth 32 million Yuan, which has become the largest single order in the history; Chongqing Wan Tai Construction and procurement of 22 million Yuan steel, the largest single bank payment.

\subsubsection{E-Commerce Can Empower Poor Households and Achieve Effective Results in Poverty Alleviation and Poverty Alleviation}

E-commerce has contributed significantly to poverty alleviation. Through the rural Taobao project, Alibaba helps the poor areas establish e-commerce service system. The retail sales of more than 280 national poverty counties were over 10 million Yuan on the Alibaba retail platform in 2016, of which more than 40 poverty-stricken counties were over 100 million Yuan in retail sales; 18 Taobao villages were emerging in the poor counties of the national level, and more than 200 villages in the provincial poor counties.

\subsubsection{E-Commerce Industry Is Focused by Capital Focus}

The investment and financing market of the Internet industry has been pre cooled affected by the macroeconomic environment, and the number and scale of financing cases have dropped. There were 1622 cases of investment and financing in the whole year, a decrease of $28.1 \%$, a financing scale of 23 billion 839 US dollars and a decrease of $26.99 \%$ in the annulus. Segments from the field of view, "Internet plus" real estate, "Internet plus" finance, e-commerce, industry website are the focus of investment. The investment and financing performance of the e-commerce industry is beautiful, the scale of financing is up to $28.48 \%$, and the average value of financing is up to US \$21 million. Among them, the new company founded by MeiTuan and Dazhongdianping got $\$ 3$ billion financing.

\subsection{5. "The Belt and Road" Drives the Rapid Development of Cross-Border e-Commerce}

The cross-border e-commerce policies have been steadily improved, and the construction projects of the free trade zone, the comprehensive pilot cities and the comprehensive experimental areas have been started, and the cross-border e-commerce processes and procedures are further simplified. The scale of cross-border e-commerce in China was 6 trillion Yuan in 2016, an increase of $24 \%$ over the same period last year. The scale of the export business is far ahead of the size of the imported electric business, in which the scale of the cross-border e-commerce transaction is 5 trillion Yuan, accounting for $82.08 \%$, and the transaction scale of the import cross-border e-commerce is 1 trillion and 200 billion Yuan, accounting for $17.92 \%$. In the field of subdivision, B2B still has absolute advantage, and B2B accounts for $88.7 \%$ of cross-border electricity suppliers.

"The Belt and Road" strategy has promoted the development of China and the countries along the explosive growth of cross-border e-trade. China's mobile phone, computer, electronic accessories, Home Furnishing products are the most popular products by the Belt and Road national market, the annual turnover of an average growth rate of more than 10 times. Imported goods, food, wine, home textiles and fruit sold higher than the other products.

\subsubsection{The Sustainable Development of e-Commerce in Rural Areas}

Rural e-commerce has ushered in the most suitable period of development, and the scale of rural Internet retailing continues to expand. In 2017, the total retail sales of rural areas in the whole country amounted to 1 trillion and 200 billion Yuan, accounting for $1 / 6$ of the total retail sales of the whole country. The scale of rural e-commerce retail sales grew rapidly. In 2017, the growth rate of e-commerce grew by $39.1 \%$ over the same period last year, which is 7 percentage points higher than that of online retail sales.

\subsection{Heze e-Commerce Made Breakthrough Progress}

Heze, is located in the southwest of Shandong Province, at the junction of four provinces of Shandong, Jiangsu, Henan and Anhui provinces. In recent years, Heze's economy has made great progress. In 2017, the whole city realized 2 GDP 82 billion Yuan (an increase of $8.5 \%$ over the previous year, and a per capita disposable income of 17 thousand Yuan. However, the overall economic development of Heze is still lagging behind the average level of Shandong Province, weak industrial base, lack of characteristic industry, lack of leading enterprises, lagging infrastructure construction and extreme scarcity of talents. Heze is also the most poverty-stricken city in Shandong. 855 villages in Heze were listed as the focal points for assistance in 2014, and there were 1.52 million poor people. Heze urgently needs to find new breakthroughs to change the poor and backward look.

Since the launch of e-commerce in 2015, e-commerce in Heze has made outstanding achievements in recent years. The rapid growth of e-commerce has become a new engine of economic development; the characteristic industry of e-commerce in Heze is obvious, which helps the transformation of traditional enterprises; e-commerce also promotes farmers' return to their hometown to create a happy rural life; e-commerce helps the poverty alleviation in Heze and promotes the inclusive development of rural society.

E-commerce in Heze city of Shandong province has made outstanding achievements in recent years, which is worth summarizing and drawing lessons from. 


\section{The Present Situation of the Development of Electronic Commerce in Heze}

\subsection{The Total Volume of e-Commerce Has Increased Rapidly and Become a New Engine of Economic Development}

The volume of e-commerce transactions in Heze has increased rapidly. Its growth rate is faster than the national average. The total number of e-commerce transactions in Heze was over 70 billion Yuan, up 49.5\%in 2015. Compared with the growth rate of $9.3 \%$ of the local GDP, e-commerce has become a new driving force for economic growth. The growth rate of e-commerce in Heze is also in the leading position in the whole country, which is 22.5 percentage points higher than the national average of $27 \%$. Cross-border E-commerce also achieved impressive results. The total amount of cross-border e-commerce transactions in the city reached 260 million US dollars, up $36 \%$ in 2015 , exceeding the level of $24.3 \%$ of the city's foreign trade growth.

The main body of e-commerce is booming, and e-commerce has become a new industry. At present, there are 2.5 million e-commerce enterprises in Heze, with an average of 1 per 400 people; the number of individual online stores has reached 130 thousand, with an average of 1 online store for every 80 people. There are more than 22 million people engaging in E-commerce. E-commerce has achieved notable results in entering the village. There have been built 501 Taobao village service stations, together with 320 postal village service stations and 256 Jingdong village service stations.

The development of electronic commerce in Heze is full of strength. In the first half of 2016, the e-commerce trade of Heze reached 53.7 billion Yuan, up 53.9\%, which is 6.5 times the growth rate of GDP $8.4 \%$. In March 2016, Heze was chosen as the "model city of e-commerce in Shandong". Cao County and YunCheng County were selected as the "demonstration counties of e-commerce in Shandong".

\subsection{E-Commerce Helps Traditional Enterprise Transformation}

E-commerce has the advantages of docking the market, shortening the industrial chain, reducing costs, and instantly achieving the goal of "buying the whole world and selling the world". Heze is rich in agricultural and forestry by-products. In the past, sales were blocked because of poor channels. E-commerce helps Heze's special products march global market, expand product sales, and promote transformation and upgrading of traditional enterprises. 10 thousand pieces of sweet potato noodles sold out online in Taobao features Heze Pavilion's opening activities. And mushroom stool achieved sales revenue of 20 million Yuan for half an hour. According to the statistical data of Heze logistics and express enterprises, the ratio of the number of packages sent to the number of packages received is reversed, from 1:3 in 2014 to
$1: 1.3$ in 2015 . In 2015 , the ratio reached $1.2: 1$ in the double eleven promotion activities, which realized the historic inflection point which was bigger than the purchase.

Yao Shun Company, with peony flower as raw material, produces a series of deep processed products, involving many fields such as medicine, daily use chemical industry, nutrition and health, food, arts and crafts, tourism and so on. Although the company's product research and development is progressing smoothly, but in the process of developing the market has been frustrated repeatedly. With the help of e-commerce platform, peony products successfully went to the national market last year. It can match the needs of consumers directly. In the three day's promotion of the opening of the Heze pavilion on Taobao, Yao Shun Company realized 4500 sales orders, and the sales revenue was 650 thousand Yuan, covering more than 10 products. At present, Yao Shun has established 7 autonomous operation platforms, such as Tmall, Taobao and shop No. 1, with average daily sales of about 500 orders.

E-commerce has opened up the international market and promoted international trade. Heze products can go all over the world online. It achieved cross-border electricity exports of US \$220 million, an increase of $50.1 \%$ over the same period last year in Heze in 2015. Ren Qingsheng, a farmer in Ding Lou village, engaged in the network sales of costumes, a month ago. He sold three sets of performance suits to Brazil with net profit 200 Yuan, while the domestic sales can earn only a few dozen Yuan. The huge profit difference made him firm up the determination of cross-border e-commerce. More enterprises find the attraction of foreign trade, and are gradually transforming into cross-border electricity providers Now, more than 200 enterprises in the city have used cross-border electricity suppliers to launch export trade.

\subsection{The Characteristic Industry Is Obvious, the Small Products Bring the Big Market}

There is a rich source of products in Heze. Moreover there are also rich agricultural products, special local products, old words, excellent handicrafts, furniture and textile products, tourism products, and so on. Among them, there are 9 famous trademarks in China and 65 famous trademarks and famous brand products in Shandong province. Some characteristic products are very suitable for online sales, such as wooden furniture, textiles, costume, special products and peony series cosmetics. There are more than 3000 kinds of merchandise on the line. The el-commerce sales of home textile products of Heze peony area exceeded 2 billion Yuan, and the annual e-commerce sales of 23 enterprises exceeded 10 million Yuan last year.

There are 432 characteristic villages with "one village and one product" in Heze, 40 townships with "one township and one industry". Heze is rich in agricultural and sideline products, and have the unparalleled advantage of developing rural e-commerce. Shandong sand food industry Co., Ltd. is a traditional roasted food enterprise in ShaTu town, mainly selling melon seeds and peanuts, with an annual output value of more than 2 billion Yuan. With the help of online shop, 
which is directly linked to the big market of the whole country, the sales volume of e-commerce was over ten million Yuan in 2015.

Heze is rich in forest resources and has the advantage of forest products. The thirteenth session of the Chinese forest products trade fair was held in Heze in September 2016. The theme of the conference is "Internet plus safety forest products". An e-commerce exhibition area was set up for the first time in the conference. Forest products trading platform was also introduced to create a never-ending Chinese forest products trade fair. During the meeting, China's Heze home industrial belt was officially launched online, and on the same day, 18 stores and 9 enterprises joined in, which effectively promoted the network sales of the home industry in Heze. Shandong Rui fan Crafts Co., Ltd. was established in 2007. It is a professional manufacturer of wood products, willow products and grass products. It owns many brands such as "Home Yi" and "Yi Liu Yuan". It includes a series of products such as shoe cabinet, bedside cabinet, clothes hat rack and dining side cabinet. RuiFan Company initially located in the export company, but business plunged into trouble with the impact of the global financial crisis. RuiFan Company is forced to transform its domestic market. With the help of e-commerce channels, the company achieved great leap forward development unexpectedly. E-commerce sales in 2012 reached 3 million, jumped to 30 million Yuan in 2013, climbed to 67 million Yuan in 2014, and exceeded 120 million Yuan in 2015. Rui Fan General Manager Li Zhen plans to move the operation center to Hangzhou in 2016, attracting high-end talents to join, and strive to achieve sales target of 200 million Yuan.

\subsection{The Rise of Rural e-Commerce, Taobao Village Clustering}

The development level of rural e-commerce in Heze is in the leading position in the country. Heze has 2 demonstration counties of e-commerce, 5 pilot counties of the Alibaba "thousand counties", 4 "Taobao towns" and 35 "Taobao villages". The number of "Taobao villages" occupies the seventh places in the National City, accounting for more than half of the Shandong province. According to the statistics of the Heze Municipal Business Bureau, there are 2.1 tens of thousands of rural e-commerce enterprises, 260 cross-border e-commerce enterprises, 5 e-commerce platforms, 10 electric business parks, with more than 10 employees.

Taobao village nurtured new industries and developed towards the trend of agglomeration. There was no performance clothing industry originally in DaJi town in Cao County. In 2009 with the birth of the first online shop, more and more farmers began to engage in production and marketing of clothing. In 2013, the net sales of apparel were200 million Yuan in DaJi town in Cao County. In 2014, sales exceeded 500 million. On the Children's Day in 2015, sales reached 500 million Yuan and 80 thousand orders. There are 208 clothing enterprises registered in DaJi town now. There are also 2600 farmers open online shops, and 44 thousand employees. The production and sales online of the performance clothing also led to the extension and improvement of the industrial chain. 18 logistics express enterprises have entered DaJi town. Photography, cloth, auxiliary materials and other supporting enterprises have come into being. There are 17 Taobao villages in DaJi town, which become the veritable Taobao town. The network sale business of the DaJi town also radiated to the other 4 townships nearby, and gradually evolved into the second largest Taobao village cluster in the country. The performing apparel industry has spontaneously formed and gathered in Cao County to help villagers accelerate the realization of the beautiful rural dream.

The development of rural e-commerce in Heze has found a new way for farmers to become rich, and has also promoted the social transformation of rural areas. The rapid development of rural e-commerce in Heze has also led to the enthusiasm of the whole city for e-commerce and entrepreneurship.

\subsection{Supporting the Rapid Development of the Service Industry, Helping e-Commerce Take off}

The rise of e-commerce in Heze has also led to the emergence and development of e-commerce supporting service industry, and gradually evolved a complete industrial ecosystem.

The e-commerce park is developing rapidly. With the rapid expansion of Internet business groups, the demand for funds and venues is becoming more and more intense, which accelerates the pace of construction of e-commerce parks. At present, 21 electricity supplier parks have been built in Heze, and 4 other parks have been completed by the end of the year. Among them, Tianhua E-commerce Industry Park is operating less than one year, entering 367 enterprises and related business team, 78 logistics enterprises, 13 express enterprises, 13 thousand employees, 56 thousand orders per day and sales more than ten million Yuan.

The logistics industry has gradually formed. It is playing an important role in supporting the development of e-commerce. There were nearly 1000 logistics enterprises in the city, 102 express enterprises and more than 6000 post village network stores until the end of 2017 , covering all the administrative villages in the city. The total logistics trade volume was 141 billion Yuan, up 9.1\%. The demand of logistics for e-commerce has stimulated the construction of logistics projects in Heze. There were 26 new business logistics projects in 2016, with a total investment of 22 billion Yuan. The first "smart logistics +" project has landed in Heze, which has built 2000 express parcels and 26 intelligent delivery terminals. It is effective to solve the final delivery problem of the last 1 kilometer.

Actively cooperate with platform enterprises to create a good infrastructure for the development of e-commerce. Heze try best to gather the resources of the platform. It has successively signed 6 strategic cooperation projects with Alibaba group, including the construction of Heze Pavilion online, the 1688 Heze industrial belt, and Ali Cloud project. Heze also signed a strategic agreement with Jingdong Group 
to promote the official operation of the Heze special store in Jingdong mall. In addition, it works closely with the "good quality Shandong" platform to connect online and offline service resources.

Establish industry associations, promote mutual help and self-discipline among Internet operators, and promote and standardize the development of e-commerce. Heze encourages township and village associations or associations to establish networks. Members of the Internet Commerce Association learn from each other, share resources and develop together. Moreover, the Internet Commerce Association has become a platform for self-discipline, exchange and training, which has promoted the healthy development of the network business ecosystem. In order to prevent fire hazards, the association of network merchants in DaJi town also organized network operators to raise funds and bought two fire engines.

The Heze e-commerce lawyers' group was established in May 2015. The lawyers' group was led by the Municipal Judicial Bureau and the municipal Commercial Bureau to escort the city's electric business enterprises. The group was composed of 30 professional lawyers. On the one hand, the lawyers' group is responsible for training relevant legal knowledge for network operators. On the other hand, it provides advice and services for contract disputes among network operators.

\subsection{Returning Home to Start a Business and Create a Happy Life}

The State Council launched the "opinions on several policies and measures to vigorously promote the innovation of all the public entrepreneurs" in July 2015, trying to create a new engine of economic development, steady growth and employment, and promote economic and social transformation and development through innovation. E-commerce has the advantages of low threshold, quick results and sustainable development. It helps to promote innovation in the public sector. Through the application of e-commerce, Heze has explored an effective way to create public innovation.

Heze has issued twenty preferential policies to actively create a good environment for entrepreneurial innovation and encourage students to return to business since 2014. Up to now, there are 21 thousand college students and migrant workers who are returning home to start their own businesses. More than 480 college student's return home to start online stores in the DaJi town, and more than 5200 young people go home to start their own businesses. Three of the Zhang Hongzheng brothers are medical graduates. In 2011, the three brothers returned to Cao County 's DaJi town ZhangZhuang village to start their own business. After several years of operation, the three brothers already have six Taobao stores, 1600 square meter factory buildings and 106 equipments, which have realized annual sales of 12 million Yuan and drove up to thousands of people. Under the guidance of the exemplary role of Zhang Hongzheng brothers, twenty other college students in ZhangZhuang village have joined the entrepreneurial team.

Almost $90 \%$ of the migrant workers in DingLou village in DaJi town have basically returned to the village to start their own businesses. At present, more than 30 families' annual sales revenue exceeds 1 million of clothing processing, of which 7 clothing processing enterprises sales is more than 5 million. There are 1300 permanent residents in the village of DingLou village. Due to the shortage of labor force, workers were also employed from Xinjiang and Henan province. The total number of migrant workers in the village reached 2000. The monthly wages of the sewing workers reached 6000 Yuan. The old women in the village joined the army of labor income generation. The seventy or eighty year old woman can embroider flowers at home, sew buttons and make buckles. Their salary is more than 50 Yuan a day. The income of the old women sitting at home for a month is equivalent to the income of planting of an acre in the past year.

\section{7. e-Commerce Helps Poverty Alleviation, and Promotes Inclusive Development of Rural Society}

E-commerce has set up a bridge between buyers and sellers, making small production directly to the country and even the world market, shortening the industrial chain and improving the marketing efficiency. Poor households can open their stores online and get rich through their own work. The DaJi town is located at the southwest end of Southwest Shandong province. Due to the backwardness of transportation and land resources, the economic developed relatively backward. There were 2 provincial poverty villages and 14 municipal poverty villages in the town. In recent years, DaJi town has taken e-commerce poverty alleviation as the main channel of poverty alleviation, accurate identification to the household, the determination of the target of poverty alleviation, and adopted a variety of help measures such as opening online stores, assisting small loans, helping employment, free handling related documents and so on. The whole town has organized multi - phase e-commerce training classes and tailoring and sewing training classes since 2015, with more than 1000 poor people participating. The village cadres taught the poor who are willing to open the net shop hand in hand, and encouraged the enterprises to give priority to the employment of poor households. There were 529 households and 1119 people out of poverty in the DaJi town in 2015. E-commerce led 896 people to shake off poverty, accounting for $80 \%$ of the poverty relief population.

E-commerce is also conducive to inclusive development, helping vulnerable groups such as the disabled get rich through labor, and gain self-confidence and happiness. Zhang Haijun, a villager of DaJi town, was deaf and dumb due to a serious illness in childhood. At first, his brother supports him who worked in Weifang City. His brother's annual income was only 30 thousand Yuan, and poor income was difficult to support a family. Later, the brother found the villagers getting rich in online business, so they opened a Taobao store. Zhang Haijun is very ingenious and learned all kinds of technology quickly. He is responsible for garment design, 
plate cutting, and cutting and sewing now. The income of Zhang Haijun's online shop was more over2 million Yuan in 2015, Zhang Haijun not only bought a car, but also married a daughter-in-law. His brother said with emotion, "It is difficult to eat a full meal once, but we are so rich that we often go to restaurants now."

\subsection{The Government Has Found an Accurate Position, Not Vacant}

In the process of supporting the development of local e-commerce, the governments at all levels in Heze have unified understanding, precise positioning, find out the difficulties and pain points of the development of e-commerce, and formulate targeted support policies. Heze first requires managers to improve the awareness of e-commerce, to promote the development of e-commerce to promote the economic transformation and upgrading, to achieve the strategic height of the curve. Jie Weijun, mayor of Heze, also made clear that all departments should "concentrate their efforts and work together to achieve joint management and precise implementation". In combination with the actual situation in the city, in order to promote the healthy development of e-commerce, the municipal government promulgated the "three year action plan for the development of electronic commerce in Heze (2015-2017 years)" to promote "scientific overtaking and later" in Heze, and planned to break through 150 billion Yuan in the volume of e-commerce transactions in 2017 and reach 350 million US dollars in cross-border e-commerce transactions.

In the process of supporting the development of local e-commerce, the governments at all levels in Heze have unified understanding, precise positioning, find out the difficulties and pain points of the development of electronic commerce, and formulate targeted support policies. Heze first requires managers to improve the awareness of e-commerce, to promote the development of e-commerce to promote the economic transformation and upgrading, to achieve the strategic height of the curve. Jie Weijun, mayor of Heze, also made clear that all departments should "concentrate their efforts and work together to achieve joint management and precise implementation". In combination with the actual situation in the city, in order to promote the healthy development of e-commerce, the municipal government promulgated the "three year action plan for the development of electronic commerce in Heze (2015-2017 years)" to promote "scientific overtaking and later" in Heze, and planned to break through 150 billion Yuan in the volume of e-commerce transactions in 2017 and reach 350 million US dollars in cross-border e-commerce transactions.

The government has also actively solved the needs and difficulties in the development of e-commerce. First, it plans and coordinates actively the construction of e-commerce Industrial Park, Logistics Park and Taobao town aiming at the urgent demand of e-traders. It also encourages the innovation loan model to encourage college students and migrant workers to return home. Second, it invests in infrastructure construction, including road construction, optical fiber access to villages and environmental improvement. The third, it increases cooperation with e-commerce platform enterprises, and promotes the platform to take root in Heze. The fourth, it promotes the establishment and autonomy of all levels of e-commerce associations, and promotes the formulation of e-commerce industry standards. The fifth, it summarizes typical cases and promotes them in the whole city. The sixth, it organizes all kinds of e-commerce related training, and constantly expands the e-commerce talent team.

\section{Problems in the Development of e-Commerce in Heze}

The development of e-commerce in Heze has made a series of achievements, showing the great potential. However, in a comprehensive comparison, the e-commerce in Heze is still in the early stages of development, and some short boards need to be urgently solved.

\subsection{Traditional Enterprises Face the Challenge of e-Commerce Transformation}

Enterprises in Heze should improve the level of e-commerce application. Statistics show that only $38.9 \%$ of the above scale industrial enterprises in Heze carry out e-commerce activities, and there is still room for broad development. The reasons for the difficulty of traditional enterprises transformation are as follows. First, the concept is lagging, some enterprises form a fixed mode of thinking in the long-term operation. They still lack of clear understanding the role of e-commerce. They also Lack enthusiasm of application of e-commerce. They cannot keep up with the changing environment. The second, they have not found a good mode of transformation. Some export enterprises still adopt mass production mode, which cannot adapt to the $\mathrm{C} 2 \mathrm{~B}$ mode of the Internet age. The third, the overall level of enterprise information is low. Some enterprises still stay in the primary stage of receiving and sending information online. They have not truly realized the integration of the resources, and have not realized the overall interaction of the enterprise value chain. The fourth, trade situation is still single, the cross-border e-commerce has just started. Heze's cross-border e-commerce transactions accounted for only $0.96 \%$ of the total import and export of the city in 2015. Compared with the domestic e-commerce level, there is a broad space for development.

\subsection{Lack of Leading Enterprises, the Overall Level of Production Needs to Be Improved}

The enthusiasm for entrepreneurship and employment of e-commerce is high in Heze. The number of e-traders is at a high level in the country, but the leading enterprises are lacking. Most of the e-traders in Heze began to operate the online shop in 2013, mainly operating performance clothes and household appliances. Although some of the annual sales of online business exceeded 5 million, but the annual sales of 
more than 10 million Yuan were scarce. Most of the e-traders have not yet got rid of the family workshop production, which is far from the modern plants. Heze's network marketing industry is still short of leading enterprises, which can play a role in attracting and guiding other enterprises.

\subsection{Lack of High-End Complex e-Commerce Talents}

Lack of talents is one of the key factors that restrict the development of e-commerce in Heze. In the survey of e-traders, it is found that e-traders generally lack comprehensive talents, especially high-end operators. The main difficulties are: first, it is short of e-commerce operation personnel, some enterprises have to move the operation center to Hangzhou and other developed areas. Second, it is lack of cross-border e-commerce complex talents. It is urgent to open the cross-border e-commerce market for the e-traders in Heze, but it lacks of complex talents who know foreign trade and e-commerce well. The third, it lacks atmosphere and habit of learning and communication between e-traders. The competition in the field of e-commerce is fierce, and the rules of the platform are not only complex and fast changing. If the e-traders lack effective communication and learning mechanism, it is difficult to grasp the latest information of the market, and it is difficult to win the competition in the fierce competition. The fourth, it lacks professional talent. It still needs a number of high-end strategy and management personnel, professional technology and design talent to join in to develop the market.

\subsection{Financing Channels Are Not Smooth}

Poor financing channels are a bottleneck that restricts the development of e-commerce in Heze. New entrepreneurs entering the market need to purchase machinery and equipment and raw materials, and the upgrading and expansion of other e-traders need financial support. Compared with traditional production enterprises, e-traders often lack assets as collateral, so it is difficult to obtain bank loans. However, the fund cooperation and mutual aid agencies of the private sector are also faced with policy and market risks such as non-compliance, risk and so on.

\section{Countermeasures and Suggestions}

\subsection{Sum up Experience and Promote the Transformation of Traditional Enterprises' e-Commerce}

Making full use of the city's media to publicize and popularize the e-commerce knowledge, summarize the typical successful cases of e-commerce, and strive to form a strong atmosphere for the promotion of e-commerce entrepreneurship and application in the city, and induce the internal power of the e-commerce transformation. Organize enterprises to visit the "QingdaoRed Collar" and other e-commerce transformation demonstration cases, and guide enterprises to find the direction and path of transformation suitable for the characteristics of the enterprises. Integrating resources, organizing and docking with larger e-commerce platform enterprises, are creating convenient conditions for e-commerce applications. It should focus on cultivating a few superior products with the characteristics of Heze, such as peony products, to help key enterprises to construct their ecommerce ecological chain, to break through, and to promote the development of the whole city and the whole industry through a class of products.

\subsection{Cultivate the Leading e-Commerce Enterprises to Enhance the Overall Competitiveness of Industrial Clusters}

To encourage Heze's potential e-traders to stand out, give priority to support and guide, form the leading enterprises and industry benchmarks for e-traders, drive other Internet stores, and enhance the overall competitiveness of the industrial clusters. Support and encourage social capital to invest in local online stores, and make bigger and stronger through shareholding system. We should encourage e-traders to establish a perfect modern enterprise system, accelerate the innovation of products and management methods, cultivate the awareness of brand and intellectual property, improve the quality of products and improve the overall level of the industry. According to the principle of developing characteristics, making large scale, giving prominence to benefit and giving full play to the enthusiasm of the main body of the market. Moreover, we should carry out the overall layout and optimize the allocation of resources, and focus on the construction of four bases: the performance clothing industry base, the outdoor furniture industry base, the peony industrial base, and the Tianhua e-commerce creation base.

\subsection{Pay Attention to Training and Communication, and Promote Talents to "Go out and Bring in"}

We should attach importance to the construction and training of qualified personnel and adopt the strategy of "going out and bringing in". On the one hand, we should encourage the existing e-traders to strengthen their internal experience exchange, and go to the developed provinces such as Jiangsu and Zhejiang to investigate and learn advanced concepts and business models. On the other hand, we should create a relaxed entrepreneurial environment, attract high-end complex talents in the field, to join the Heze city of e-commerce business enterprise, especially to encourage migrant workers to return home to Heze. At last,, we should support the establishment of e-commerce related disciplines in three secondary and tertiary institutions in Heze, and encourage students to participate in e-commerce entrepreneurship and employment. We should actively build a bridge between talent cultivation and demand between schools and e-commerce enterprises, and establish a training mechanism for practical talents.

\subsection{Promoting Financial Innovation and Providing Financing Support for SMEs and e-Traders}

We should increase financial support for e-commerce and 
improve the multi-channel investment and financing mechanism to adapt to the development of e-commerce. Special start-up funds should be given to the poor households in e-commerce for key support. We should encourage financial institutions to innovate services, use large data and other technologies to establish enterprise archives, provide multi-level financing services for e-commerce, and enrich the ways and channels for the financing of social capital. We should encourage social capital to participate in the construction of e-commerce in Heze, and guide enterprises with a certain scale to introduce partners or venture capital into different channels. We have given policy and operational guidance to the established township financial mutual aid cooperatives to help cooperatives set up early warning mechanisms to prevent risks.

\section{Summary}

Heze has gone out of the road of developing e-commerce with local characteristics. The outstanding achievements have been achieved in costume and wood Home Furnishing field of e-commerce. While developing the economy, e-commerce promotes rural social transformation and effectively helps the poor to get rid of poverty and become rich. Heze's e-commerce development experience is worthy of reference for other cities in China.

\section{References}

[1] Ye Shaoxia, The role of e-commerce in promoting the core competitiveness of enterprises $[\mathrm{J}]$. Business culture (second half month), 2012 (02).

[2] Liu Junbin, Strategies for transformation and upgrading of e-commerce in small and medium-sized enterprises [J], Economic guide, 2011 (04).

[3] Wu Qing Li, Electronic Commerce: concept, misunderstanding and future $[\mathrm{J}]$, Journal of Nanjing University of Posts and Telecommunications (SOCIAL SCIENCES), 2010 (2).

[4] Feng Ji, On the construction of enterprise competitiveness under the condition of network economy [J], Jiangsu business theory. 2008 (09).

[5] Wang Xiangdong, "New agriculture, rural areas and e-commerce", China Agricultural Science and Technology Press, 2015.

[6] Ye Xiumin, Wang Xiangdong, "Dongfengcun survey: rural e-commerce" sand collection mode ", social sciences literature press, 2015.
[7] Ali Research Center, China Taobao Village Research Report (2017), December 2017.

[8] Wei Yanan, "to talk about the six problems existing in the current rural electricity supplier", 2017 China Hanzhoung e-commerce forum, April 2017.

[9] Ye Xiumin, "County electric business: precision" poverty alleviation "new prescription", "decision making", 20162.

[10] Ye Xiumin, The ten year summary of Sha Ji mode, Internet world, February 2017.

[11] Ye Xiumin, The "Internet plus" under the background of the study on the operation mode of "standard of poverty alleviation, informatization construction, in 201710.

[12] Ye Xiumin, "The Enlightenment of Jinhua's el-commerce turning overtaking", Internet world, 20173 issue.

[13] Tang FeiFei, New model of agricultural e-commerce under the background of new urbanization construction [J]. Economic and trade practice. 2016 (18).

[14] Qian Jun, Li Qiang, Ma Jun, Key issues and Countermeasures in the development of rural e-commerce in Yangzhou under the background of new urbanization [J]. Jiangsu business theory. $2017(10)$.

[15] Long Huafang, Liu Xian, Wu Nan, Gao Tong, Research on the role and influence of rural e-commerce in Henan's precision poverty alleviation [J]. Innovation and technology. 2017 (12).

[16] Zhao Xia, Zhang Jie, Zheng Tianai, Meng Baocheng, Rural e-commerce precise poverty alleviation model research $[\mathrm{J}]$. Enterprise science and technology and development. 2017 (01).

[17] $\mathrm{Hu}$ FAgang, The role, problems and Countermeasures of China's rural e-commerce on consumption $[\mathrm{J}]$, Business economics research. 2018 (04).

[18] Mei Guiquan, The current situation and improvement strategy of rural e-commerce development [J]. farmer's staff. 2018 (03).

[19] Cheng YiYuan, The significance and problems of rural e-commerce development [J]. Journal of TaiYuan City Vocational College. 2018 (01).

[20] Li Yingting, The dilemma and innovation path of rural e-commerce: [J]. Modern marketing (next issue). 2018 (02).

[21] Some thoughts on the development of rural e-commerce [J]. Li Huifan. Chinese and foreign entrepreneurs. 2017 (33).

[22] Gong Yu, China's rural e-commerce development status, problems and Countermeasures [J]. Friend of farmers becoming rich. 2018 (02). 